\title{
Lucrècia Borja. L'alteració d'una identitat i l'errònia atribució de la pintura de Flora de Bartolomeo Veneto
}

\section{Lucrezia Borgia. The alteration of identity and the erroneous attribution of the painting of Flora Bartolomeo Veneto}

\author{
Alexandre Vico \\ alexandrevico748@gmail.com \\ Universitat de Girona
}

\begin{abstract}
Resum: Aquest treball pretén emfatitzar l'errònia identitat que ha arribat fins als nostres dies de Lucrècia Borja i l'equivocada atribució que se n'ha fet d'alguns retrats. Com ara, la pintura de Flora (c.1520), pintada per Bartolomeo Veneto, que ha passat a la història com una indissoluble identificació de Lucrècia. Els estudis actuals han demostrat que representa un model ideal influit pel context literari probablement relacionat amb Pietro Bembo. Durant el Renaixement, els retrats representen molt més que una identitat concreta i mimètica. Són suports de prestigi i transmissió ideològica, de virtuts morals, memòria, etc. En l'àmbit artístic venecià de principis del segle XVI sorgeixen múltiples retrats femenins de difícil identificació que la crítica freqüentment ha relacionat amb cortesanes, amants, dones. Moltes, però, representen ideals poètics a través dels quals la pintura demostra la seva capacitat de rivalitzar amb la poesia quant a demostració de l'ideal estètic de la bellesa. Aquest breu treball pretén examinar les successives interpretacions historiogràfiques que erròniament han identificat la pintura de Flora amb Lucrecia Borja a causa del valor eròtic pejorativament relacionat amb ella, però també vol posar èmfasi en les altres propostes que han permès que l'obra sigui interpretada amb l'exegesi més adequada.
\end{abstract}

Paraules clau: Lucrècia Borja, Pol Coronado, Retrat, Bartolomeo Veneto, Flora

\begin{abstract}
This study intended to emphasize the identity has been wrong that has reached our days of Lucrezia Borgia and the wrong attribution has been made of some pictures. One of the most paradigmatic paintings is Flora (c.1520), painted by artist Bartolomeo Veneto. This work has gone down in history as one indissoluble portrait of Lucrezia, but recent studies have shown represents an ideal model influenced by the literary context probably related to Pietro Bembo. During the Renaissance, portraits represent much more than a specific and mimetic identity. They are supports of prestige and ideological transmission, of moral virtues, memory, etc. In the Venetian art scene of the early sixteenth century, multiple female portraits often difficult to identify that criticism have related courtesans, mistresses, wives. Many of these paintings also represent poetic ideals through which painting demonstrate its ability to compete with poetry in terms of demonstrating the aesthetic ideal of beauty. This short paper aims to examine the successive historiographical interpretations erroneously identified the painting of Flora with Lucrezia Borgia due to the erotic value related to her pejoratively, but also wants to highlight other proposals that have allowed the work to be performed with the most appropriate exegesis.
\end{abstract}

Keywords: Lucrezia Borgia, Pol Coronado, Portrait, Bartolomeo Veneto, Flora 
Alexandre Vico. Lucrècia Borja. L'alteració d'una identitat i l'errònia atribució de la pintura de Flora de Bartolomeo Veneto

\section{Justificació.*}

El present article sorgeix com una de les moltes respostes i conseqüències positives de la celebració a Xàtiva del I congrés Història, Cultura i Identitat durant els dies 4 i 7 de maig de l'any 2016. L'expectació generada per aquest esdeveniment i els múltiples debats tractats al llarg de les jornades, van posar de manifest la necessitat d'esclarir i refutar múltiples tòpics erronis arrelats amb relació a la família Borja. En el mateix lloc on es van celebrar les sessions, l'aula capitular del convent de Sant Domènec, també va tenir lloc una exposició anomenada Deconstucting ab Borjas. Una original proposta que va centrar la seva atenció a_replicar i reinterpretar l'univers borgià que ha arribat fins als nostres dies corromput per unes connotacions pejoratives. Retratant els fills de Roderic de Borja com si fossin coetanis nostres, alguns dels treballs exposats captaven perfectament la necessitat d'humanitzar novament $i$ analitzar des d'una perspectiva actual -i diguem que menys maquiavèl lica- els membres d'aquesta nissaga de valencians.

\section{Expectació davant l'obra de Pol Coronado.}

De les diverses obres pictòriques que ocupaven les capelles laterals, n'hi va haver una que va despertar una impressió singular que aviat es va fer palesa entre els assistents del congrés. Entre doctes arguments de Joan Francesc Mira en la primera de les jornades, l'escriptor, antropòleg i sociòleg va criticar la desencertada fortuna amb què avui dia es coneix la família; especialment la visió que es té de Lucrècia. I afegia que ha arribat fins els nostres dies amb una fama corrompuda. Per Mira, les connotacions eroticosexuals associades des dels seus dies a la jove tenen com a resultat en_l'actualitat la construcció d'un estereotip distorsionat amb què gairebé es pot equiparar Lucrècia amb una «cicciolina» del seu temps; quelcom perfectament reflectit en l'obra exposada «Lucrecia Borgia» de Pol Coronado. Durant les comunicacions i les intervencions del congrés, aquesta voluntat de sanejar la immerescuda fama incestuosa i criminal dels Borja va ser el principal leitmotiv. Es van plantejar qüestions estrictament borgianes com: comprendre les complicades conjuntures de les seves vides, valorar quina va ser la recepció que van tenir a Roma com a estrangers, comparar si les accions que Roderic de Borja va prendre com a papa Alexandre VI diferien tant de les que altres papes anteriors havien dut a terme, etc. Tots aquests temes d'obligada revisió es van aprofundir des d'una perspectiva crítica, rigorosa i allunyada de les interferències novel lesques dels darrers segles.

\footnotetext{
* A Purificació Mascarell i Paco Cerdà per la seva gentilesa durant la meva estada a Xàtiva.
} 
Alexandre Vico. Lucrècia Borja. L'alteració d'una identitat i l'errònia atribució de la pintura de Flora de Bartolomeo Veneto

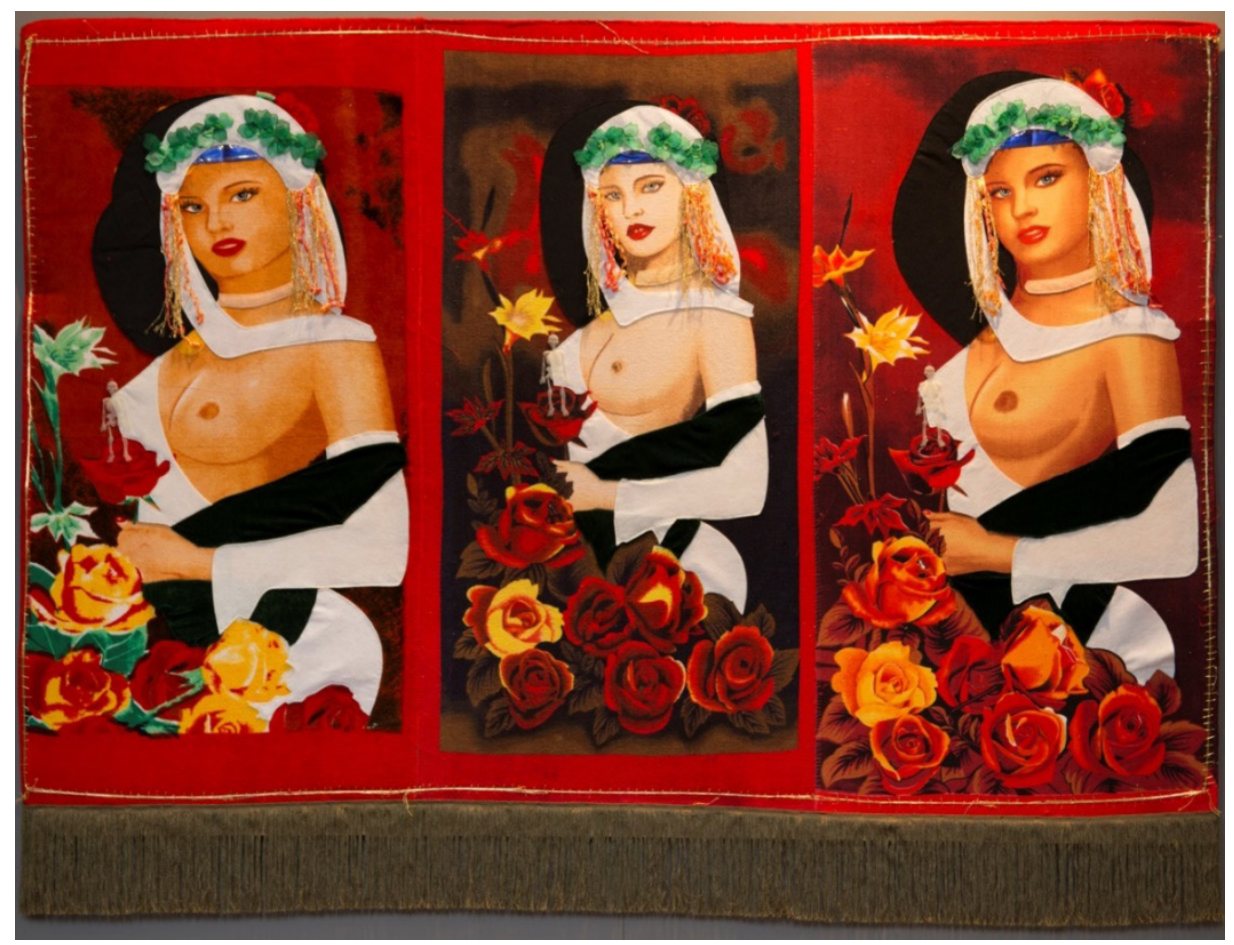

Pol Coronado. Lucrecia Borgia (2016). Tècnica mixta 160x 215 cm.

Com s'ha dit, el triple retrat de Pol Coronado va causar certa polèmica precisament per l'exagerada i sarcàstica representació que va proposar de Lucrècia Borja. Tot i que durant els últims anys han estat diverses les agosarades relectures artístiques que han centrat l'atenció en els retrats i la fama de Lucrècia -com per exemple va demostrar Antonio de Felipe l'any 2010 a Gandia-, la proposta de Coronado esdevé un tour de force conceptual i formal en relació a resta de produccions. Porta al límit la confusió i el capgirament entre la realitat i la ficció associada a Lucrècia Borja, mostrant un explícit resultat de la falsificació i diguem-ne que de la «pirateria» que ha sofert la seva figura històrica en els últims segles. Mitjançant la multiplicació d'un mateix model figuratiu obtingut de tovalloles barates comprades en establiments costaners, Coronado realitza aquest ready made en què s'utilitzen diferents materials combinant diverses impressions que parteixen d'una mateixa imatge. Cadascuna de les tres representacions femenines presenta subtils alteracions, tant d'escala com formalment. Cada Lucrècia és passada volgudament per un procés de deformació que pretén posar de manifest les conseqüències de la frívola societat comercial que ha aprofitat la «malversació» biogràfica i el desconeixement, per convertir-la en la femme fatale del Renaixement per antonomàsia; per situar-la en el que banalment consideraríem el top ten de personatges malignes de la història de la humanitat. El format triple emprat pel perspicaç artista murcià no només juga amb les connotacions sacres i religioses que evoca la tipologia del tríptic -i que en qualsevol cas busquen denotar la condició herètica imposada injustament a Lucrècia-, sinó que alhora demostra que si no es reivindica i recupera la realitat històrica de la jove, els múltiples perfils que poden configurar la 
Alexandre Vico. Lucrècia Borja. L'alteració d'una identitat i l'errònia atribució de la pintura de Flora de Bartolomeo Veneto

seva personalitat -com a filla de Roderic, com a mare, com a duquessa de Ferrara, etc.-, sempre patiran el mateix destí i seran aspectes afectats per aquestes obscenes i pretensioses connotacions que el pas del temps ha permès arrelar.

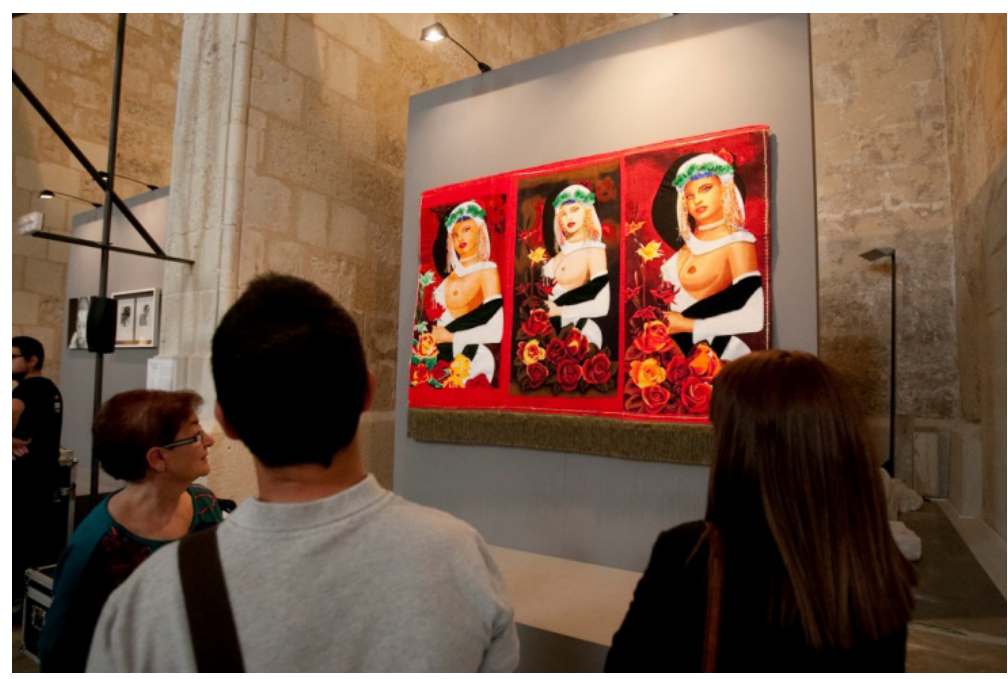

L’obra de Pol Coronado va generar múltiples reaccions i interès per part dels assistents.

Els macabres i lascius atributs atorgats a Lucrècia queden perfectament reflectits en l'obra de Coronado, ja sigui mitjançant l'orgullosa exhibició d'un pit -més voluptuós que artístic-, la provocadora mirada, la construcció escènica submergida en passionals tons rogencs farcits de roses, o fins i tot la subtil inclusió d'un esquelet que remet a la malícia homicida que també se li ha atribuït. De manera que aquest treball no només va atraure la mirada dels visitants per la seva vivacitat cromàtica, sinó perquè els continguts que s'hi representen de manera dramatitzada concordaven a la perfecció amb els propòsits de les jornades i el desig d'eradicar la «llegenda negra» que tant ha contaminat la fama dels Borja.

En qualsevol cas, no totes les respostes suscitades davant aquesta obra van ser iguals. En particular, els més aguts connoisseurs $\mathrm{i}$ alguns historiadors de l'art presents, ràpidament van percebre deutes vers_aquell cèlebre retrat de Flora realitzat per Bartolomeo Veneto que el pas del temps ha volgut identificar amb Lucrècia. El mateix creador del triple retrat, l'esmentat Pol Coronado, confirma haver-se inspirat en la fascinant i qüestionada pintura de Veneto. La controvertida atribució del retrat realitzat pel cinccentista venecià tampoc s'ha salvat de la negativa fortuna de la nissaga Borja. Amb el pas dels segles va anar perdent la seva identitat com a retrat al legòric de Flora, fins a veures'hi una incongruent i desencertada representació de la filla del papa Alexandre VI. 
Alexandre Vico. Lucrècia Borja. L'alteració d'una identitat i l'errònia atribució de la pintura de Flora de Bartolomeo Veneto

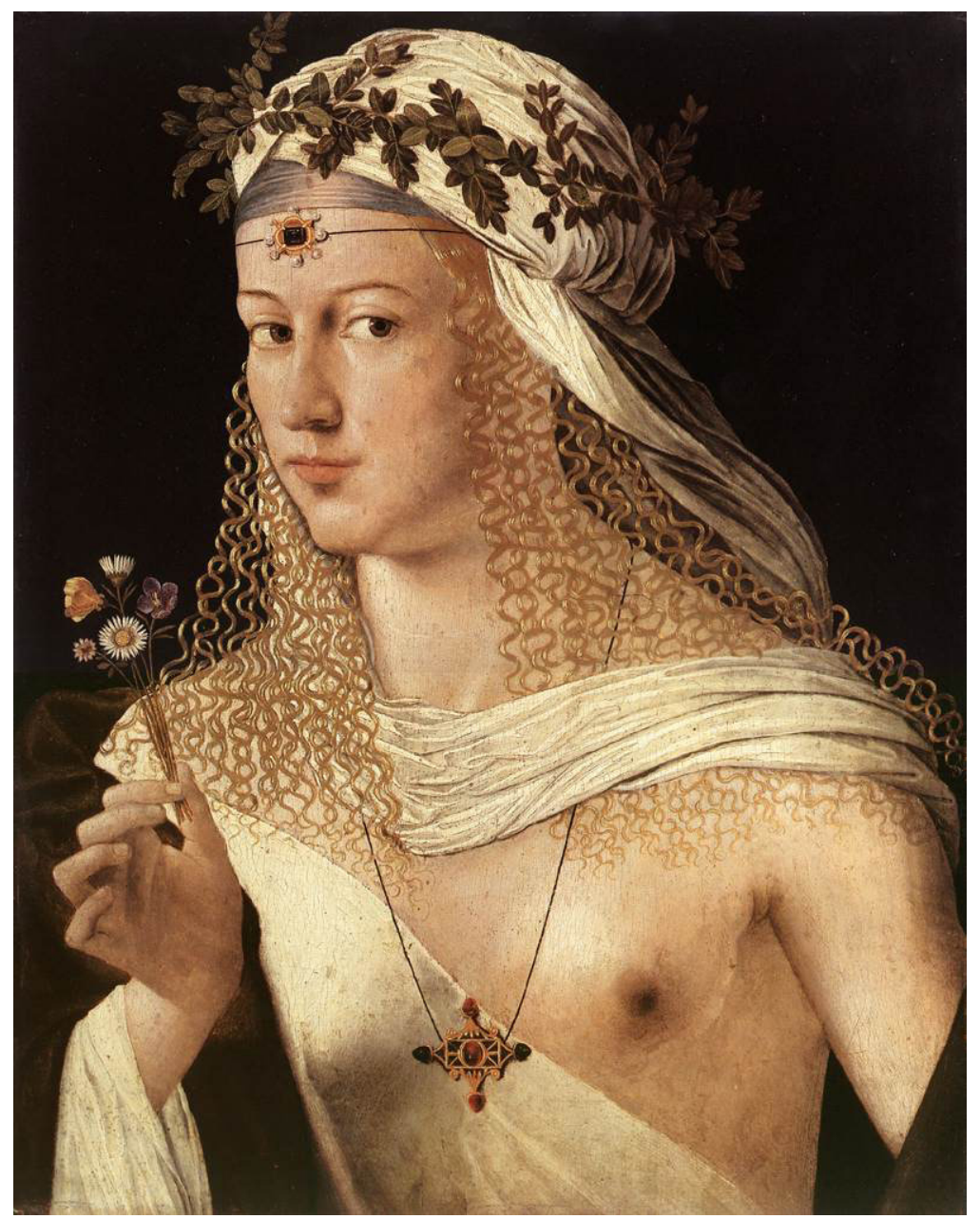

Bartolomeo Veneto. Flora (c. 1520). Städelsches Kunstinstitut, Frankfurt. Tremp i oli sobre taula. 44x $35 \mathrm{~cm}$.

SCRIPTA, Revista internacional de literatura i cultura medieval i moderna, núm. 9 / juny 2017 / pp. 286-311 ISSN: 2340 - 4841 doi:10.7203/SCRIPTA.9.10348 
Alexandre Vico. Lucrècia Borja. L'alteració d'una identitat i l'errònia atribució de la pintura de Flora de Bartolomeo Veneto
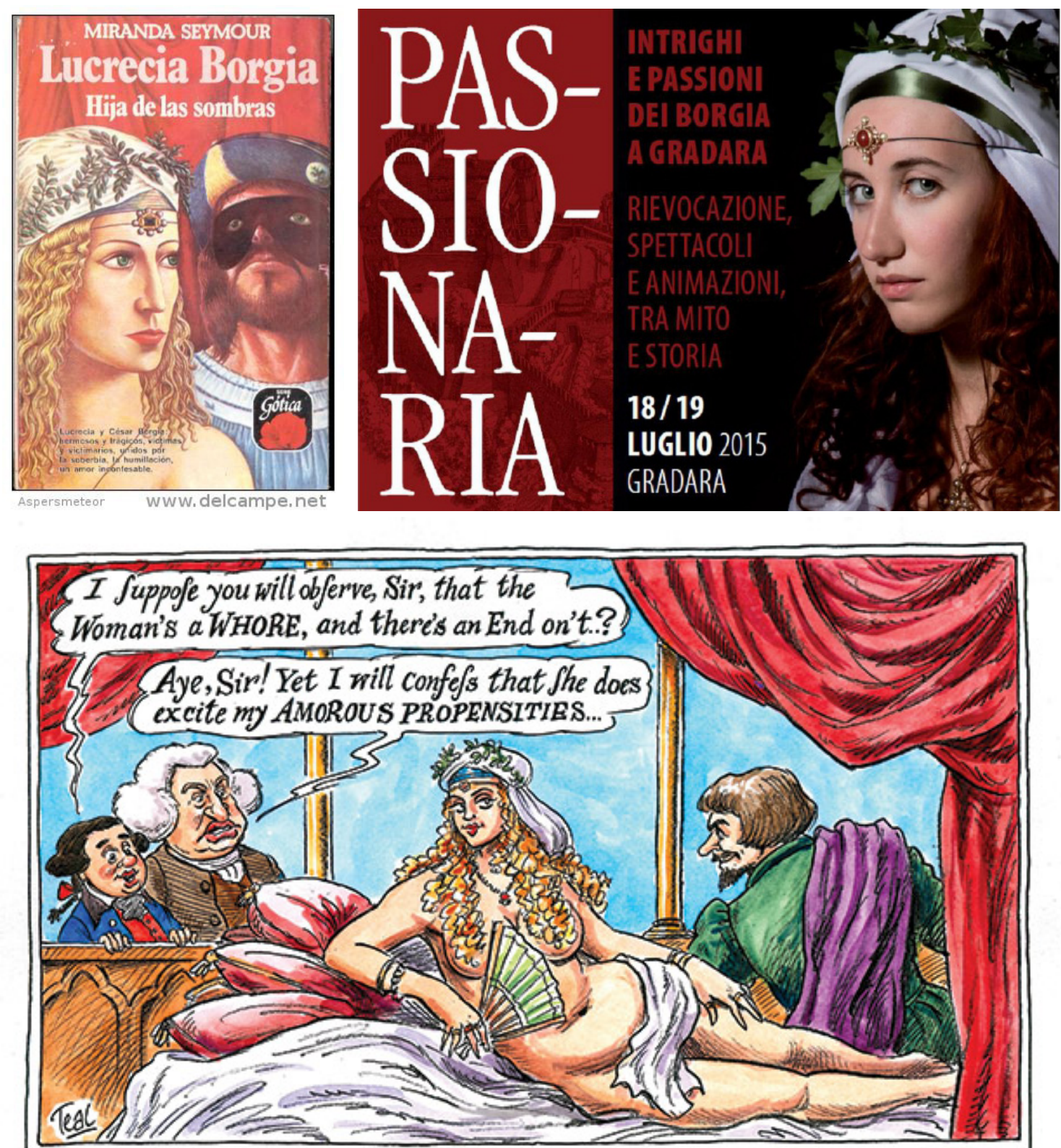

JOHNSON \& BOSWELI - Their ADVENTURES in HISTORY. N6.3 - In the BOUDOIR of LUCREZIA BORGIA.

Alguns dels múltiples exemples que erròniament han fet ús del retrat de Flora de Bartolomeo Veneto per referir-se a Lucrècia Borja. 
Alexandre Vico. Lucrècia Borja. L'alteració d'una identitat i l'errònia atribució de la pintura de Flora de Bartolomeo Veneto

Portades de llibres, postals, vinyetes còmiques, merchandising, espectacles, i un llarg etcètera de suports han fet ús d'aquesta emblemàtica imatge. Per a les grans masses, el retrat de Veneto s'ha erigit sens dubte com una icona indissolublement lligada a la tergiversada sensualitat de Lucrècia Borja. Sembla que gairebé ningú dubti que en aquesta agosarada pintura s'hi representi una dona tan luxuriosa com la «falsa» Lucrècia que avui coneixem. És per això que, recuperant el fil crític i de rigor científic que va predominar en les jornades del pretèrit congrés, a continuació es buscaran possibles respostes que justifiquin aquestes problemàtiques i per què amb el pas del temps han consolidat aquestes opinions errades.

\section{L'artista}

En primer lloc, caldrà analitzar la fortuna crítica del creador d'aquest controvertit retrat, Bartolomeo Veneto (c.1480 - Torí 1531). Format a Venècia sota les ensenyances de Gentile Bellini i influït per les propostes d'Albrecht Dürer, aquest pintor va caure en l'oblit poc després de la seva prematura mort. Una de les causes per les quals la personalitat artística de Veneto ha restat en una boirina de desconeixement té la seva justificació en l'absència de referències o mencions en fonts importants de la historiografia artística com les Vite de Giorgio Vasari o les també biografies d'artistes de Carlo Ridolfi (Pagnotta 2002). Ni tan sols es coneixen exactament els seus orígens i se'n discuteix una procedència llombarda o bé veneciana que encaixaria amb el topònim del cognom. La manca de testimonis documentals biogràfics i especificitats sobre la seva producció pictòrica suposa una de les causes per les quals posteriorment s'han confós tant la seva data de naixement com les identitats retratades en les seves obres. No obstant, han arribat als nostres dies referències de la seva formació i activitat a principis de segle a l'esmentada capital de la república de la Serenissima i d'almenys dues estades a la cort dels Este a Ferrara: la primera, entre 1505 i 1508 -poc després del periple venecià- i, en una segona ocasió, vora el 1511 (Burgess 2011).

Sabem que Veneto va retratar Lucrècia Borja, segurament en la darrera estada a Ferrara. D'aquest retrat segur, només en conservem algunes còpies realitzades per altres pintors; però aquest tema es tractarà més endavant. En qualsevol cas, i presentant un dels primers motius pels quals hem de refutar que la pintura de Flora retrata la duquessa Borja, és precisament la seva datació, considerada generalment posterior al moment en què Veneto treballava a la cort ferraresa. La Flora de Veneto, se sol datar, doncs, entre 1515 i 1520. Però altres experts, com Laura Pagnotta, consideren que pel seu estil i paral lelismes amb altres pintures de Veneto com la Circumcisió (1506), hauria de situar-se a la primera dècada del segle XVI (Pagnotta 1997: 45), moment en què -segons documents d'arxiuLucrècia Borja va comissionar moltes obres a pintors, dauradors i altres artesans (Franceschini 1997: 643). Aquesta hipòtesi també és recolzada per Laureati, qui considera que de les dues estades que Bartolomeo Veneto va passar a Ferrara, la més perllongada hauria permès al pintor obtenir encàrrecs de major prestigi en comparació a les insignificants comissions que hauria rebut tan punt va arribar a la cort ducal (Laureati 2002: 62). 
Tot i les moltes propostes historiogràfiques, les datacions de Flora són encara incertes; oscil len dècades amunt o avall segons l'estudiós, però no s'acaba d'esclarir si va ser una obra pintada a Ferrara mentre Veneto realitzava altres retrats i tasques artístiques variades, o per contra -tal i com es percep en el seu domini tècnic i estil madur-, la va realitzar posteriorment en altres contrades i la va enviar al cercle cortesà ferrarès. El que sí és compartit de manera unànime per la crítica és que l'explícit erotisme de la representació evidencia que va ser una obra concebuda per col locar-se en un lloc de visualització restringida, destinada a uns espectadors cultes i avesats al món literari com eren els Este.

Seguint amb les referències biogràfiques del pintor -també documentat com «Bartolomeo da Veneziia» ${ }^{1}$-, Milà, Pàdua i Brescia van ser algunes de les ciutats on va seguir treballant durant la seva breu vida. Va deixar una producció pictòrica dispersa i heterogènia que posa de manifest una personalitat artística constantment mal leable i receptiva davant l'empremta d'artistes com Leonardo da Vinci -que marcaven les tendències estilístiques a Milà-, o bé respecte a les particularitats artístiques de cadascuna de les zones on va treballar. Veneto va morir sobtadament a Torí el 1531, mentre estava en plena activitat artística $i$-malgrat que referències cronològiques siguin fal libles respecte a la data de naixement- es calcula que tindria poc més de cinquanta anys (Pagnotta 1997: 109). Així doncs, el perfil de Bartolomeo Veneto és el d'un artista inquiet, sempre sensible a les propostes nòrdiques -com l'anteriorment mencionat Dürer- $\mathrm{i}$ als múltiples estímuls regionals amb què va crear una síntesi personal de gran destresa tècnica i d'una qualitat apreciada pels seus contemporanis.

No va ser fins a mitjan segle XIX quan les pintures de Veneto van passar de romandre en diverses col leccions privades a ser adquirides pels grans museus europeus. Gràcies a aquestes operacions, les pintures de Veneto han estat objecte de múltiples estudis a fi d'apropar-se a una correcta anàlisi i interpretació de totes elles. Però no totes les hipòtesis respecte a la identitat que representa la pintura de Flora han coincidit.

\section{Interpretacions historiogràfiques de Flora.}

L'any 1891 la pintura de Flora va ser adquirida pel Städelsches Kunstinstitut de Frankfurt i va ser considerada una obra d'escola florentina. Aquest any ha de ser entès com el preludi d'una llarga llista de propostes i atribucions que van passar de considerar la Flora com a obra de Dürer -datantla vora el 1495- (Berenson 1916: 259), a proposar-ne un vincle proper als tallers de Botticelli, Piero di Cosimo o Signorelli (Wyzewa 1891: 346). La representació de la deessa romana de les flors, la natura i la primavera -fàcilment identificable pels atributs florals- va confondre molts estudiosos que ràpidament consideraven la pintura de Bartolomeo Veneto una més de les produccions artístiques florentines de temàtica profana i d'arrel neoplatònica. A més, l'eclecticisme i síntesi d'estímuls

1 Amb relació a la identificació en fonts primàries d'aquest i altres artistes actius a la cort ducal de Ferrara, vegeu: Franceschini (1997). 
Alexandre Vico. Lucrècia Borja. L'alteració d'una identitat i l'errònia atribució de la pintura de Flora de Bartolomeo Veneto

artístics -abans citats- nòrdics i de la Itàlia septentrional que caracteritzen l'obra de Veneto van suposar un maldecap per a molts historiadors i interessats en la matèria artística. Però el moment en què es van començar a proposar interpretacions $i$ atribucions més interessants $i$ encertades va ser al segle XX.

A principi d'aquest segle, Karl Huysmans va quedar fascinat pel refinament i caire luxuriós d'aquest retrat i va presentar-ne una particular interpretació. Huysmans no només estava convençut -com suggeria Wyzewa- que Flora pertanyia a l'àmbit artístic florentí de finals del Quattrocento, sinó que proposava una identificació de la jove representada en relació als valors profans, eròtics i demoníacs assignats a Giulia Farnese, cèlebre i bella amant d'Alexandre VI (Huysmans 1905). La fantasiosa i poc científica proposta d'aquest escriptor francès evidenciava l'empremta romàntica deixada ja per les manifestacions literàries de Victor Hugo i Alexandre Dumas. Ambdós escriptors -juntament amb el llibretista Felice Romani, el compositor Gaetano Donizetti, etc.- no eren els culpables directes de les deformacions relacionades amb els Borja, però sí que van contribuir a fer quallar un fals mite sorgit a partir dels perniciosos comentaris cinccentistes de Johannes Burchart ${ }^{2}$ mentre la família de valencians eren a Roma. En qualsevol cas, el pas del temps i els múltiples comentaris dels detractors dels Borja van cristal litzar al segle XIX i van establir una adulterada mitologia i definitiva degeneració de la història dels Borja.

Tornant a la proposta artística de Huysmans, aquesta va donar pas a la posterior exegesi que en va fer Georg Swarzenski, qui per primer cop va relacionar la deessa retratada amb Lucrècia Borja i la seva condició de duquessa de Ferrara (Swarzenski 1922). Per defensar aquesta identificació, Swarzenski s'aferrava al fet que Bartolomeo Veneto va realitzar algunes obres a Ferrara en una cronologia propera a la que es situa aquest retrat. Sens dubte Swarzenski devia haver estudiat el retrat amb minuciositat, entre d'altres raons, perquè des de l'any 1906 va ser director del Städelsches Kunstinstitut de Frankfurt, lloc on encara es conserva el retrat. L'alemany valorava la possibilitat que es tractés d'un retrat idealitzat, però no va deixar d'apuntar a la identitat de Lucrècia Borja.

Anys després, André de Hevesy seguia el mateix parer que Swarzenski, però aportant nombroses analogies formals entre els possibles retrats de Lucrècia realitzats per Pinturicchio, les medalles amb la seva efígie, etc. (Hevesy 1932). Hevesy va tenir en compte un detall determinant en la justificació dels seus plantejaments: la data de mort de Lucrècia, el 24 de juny de 1519. Els trets estilístics de Flora, identificables tant en la dècada de 1510 com als últims anys de Veneto, van generar una purificació de datacions entre les quals Hevesy considerava que la pintura hauria estat realitzada entorn el 1520-1525. La proposta d'aquesta tardana cronologia va permetre a Hevesy argumentar que, de la mateixa manera que Alfons d'Este va encarregar a Dosso Dossi que fes un retrat del seu pare Hèrcules I d'Este anys després d'expirar, la pintura de Flora també hauria respost a una voluntat de rememoració post mortem pel dol que va deixar Lucrècia entre els ferraresos, ja que malgrat les males llengües de Roma, en aquesta terra se'n va lloar la seva devota santedat.

2 També citat com Johann Burchard o Johannes Burkhart (Niederhaslach, c. 1450 - Roma, 1506).

SCRIPTA, Revista internacional de literatura i cultura medieval i moderna, núm. 9 / juny 2017 / pp. 286-311 ISSN: 2340 - 4841 doi:10.7203/SCRIPTA.9.10348 
Alexandre Vico. Lucrècia Borja. L'alteració d'una identitat i l'errònia atribució de la pintura de Flora de Bartolomeo Veneto

Com s'ha dit, l'esquelet de les teories d'Hevesy consistia en una coherent però també arriscada compilació i comparació entre diverses representacions i retrats hipotètics de Lucrècia amb relació a altres de segurs. Entre les obres contrastades, hi figuren els mencionats frescos que Pinturicchio ${ }^{3}$ va realitzar als anomenats Apartaments Borja del Palau Apostòlic Vaticà, però sobretot cal destacar altres pintures de Bartolomeo Veneto com Salomé o una còpia del mateix autor que amb seguretat retrata Lucrècia i que a continuació descriuré. En definitiva i com a resolució d'aquests procediments analítics, Hevesy es va posicionar a favor dels plantejaments de Swarzenski, considerant que el retrat de Flora no només representava una dimensió fantàstica i de «cosa galante» típica de les contrades artístiques venecianes de la primera meitat del segle XVI, sinó que estava estretament lligat a la duquessa i el modus vivendi de la cort de Ferrara.

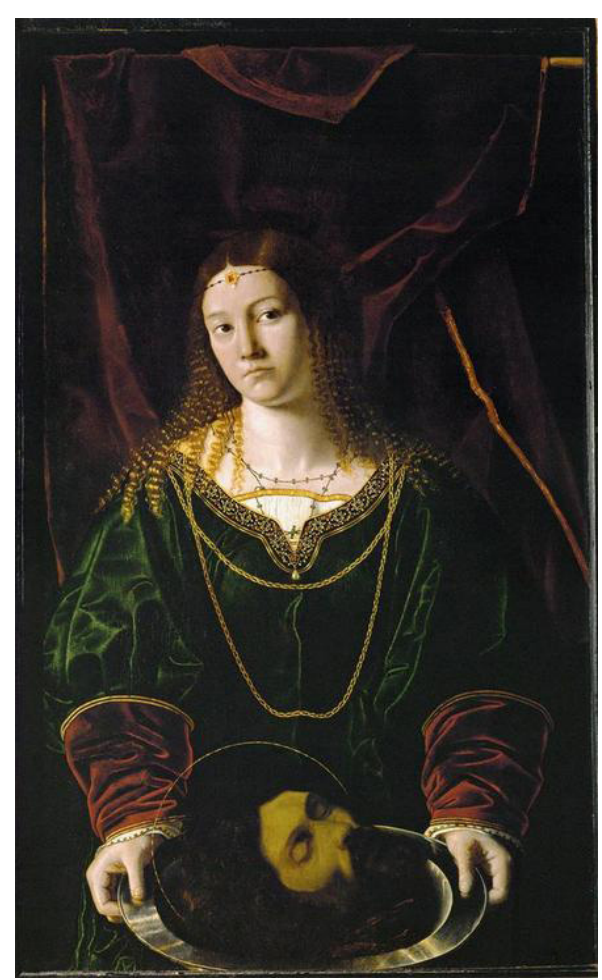

Bartolomeo Veneto. Salomé (c. 1520). Gemäldegalerie, Dresden.

\section{Els retrats de Lucrècia Borja}

Arribats a aquest punt, cal esmentar de manera fugaç un altre debat encara viu amb relació als retrats que de ben segur representen Lucrècia. Resulta imprescindible parar atenció a aquestes produccions per tal d'obtenir informacions que ens permetin identificar correctament qui retrata

3 Bernardino di Betto di Biagio (Perusa, 1454-1513), més conegut pel malnom de «Pinturicchio». 
Alexandre Vico. Lucrècia Borja. L'alteració d'una identitat i l'errònia atribució de la pintura de Flora de Bartolomeo Veneto

Flora. Segons les fonts, Bartolomeo Veneto va pintar un retrat de Lucrècia Borja a l'entorn dels anys 1510. Aquest retrat original hauria estat de gran importància no només pel valor que tenia per a la família dels Este, sinó perquè, com es veurà, se'n van fer diverses còpies. Fa uns anys, sembla que es va identificar aquest primer i influent retrat (Bellonci 2003). Ara bé, abans d'aquesta atribució, només es coneixien poques còpies que amb certesa s’identificaven amb Lucrècia. ${ }^{4}$ Una d'elles era posterior a l'original de Bartolomeo Veneto i va ser encarregada -a un pintor desconegutper Signor Nessi, bisbe, erudit i col leccionista, que desitjava incorporar una representació de la duquessa a la seva col lecció de personatges il lustres a la vil la de Como. ${ }^{5}$ Aquesta còpia, molt probablement adaptant-se a la composició de la resta de retrats il lustres de Nessi, mostrava l'efígie de Lucrècia Borja dins un marc oval. Disposem de poques imatges d'aquesta pintura, ja que després de la Segona Guerra Mundial vam perdre el seu rastre. Una altra còpia, de format quadrangular i possiblement anterior a la de Nessi, ha viscut una millor fortuna i avui es conserva al Museu de Belles Arts de Nimes. Fins i tot, no tenim per què creure que tals còpies s'haguessin fet de l'original de Veneto. Una hipòtesi possible és que el retrat de Signor Nessi fos la còpia de la primera còpia, és a dir, dupliqués la Lucrecia Borja de Nimes.
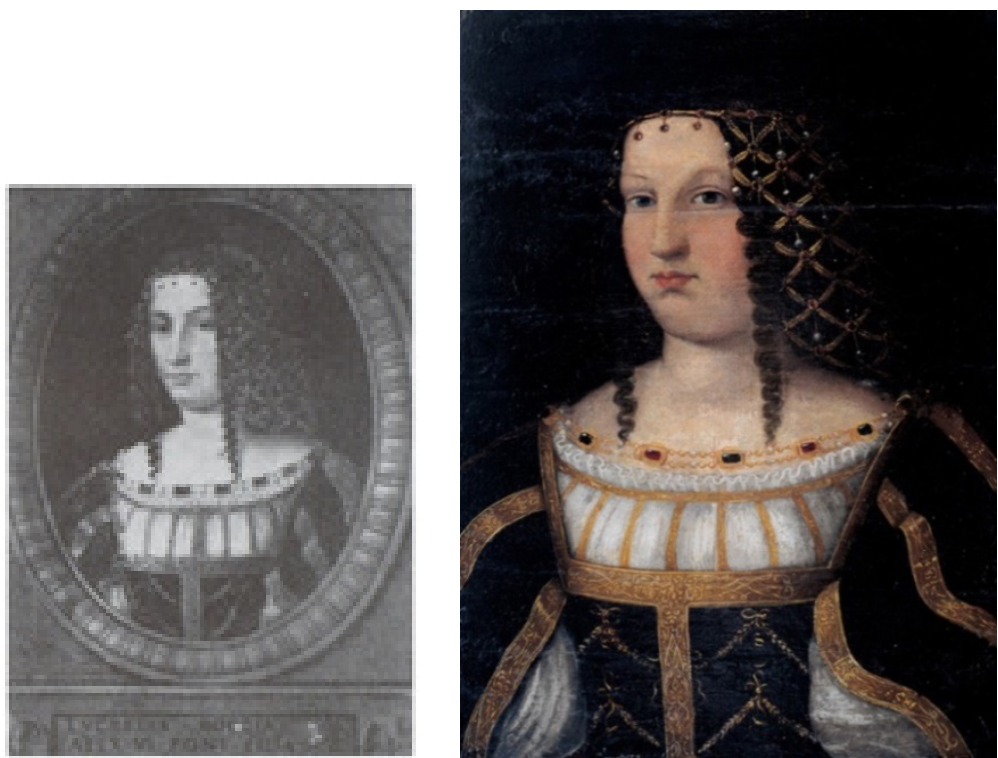

Còpia de Bartolomeo Veneto. Retrat de Lucrècia Borja (c.1510-1520) Desapareguda. 33x 24 cm Còpia de Bartolomeo Veneto. Retrat de Lucrècia Borja (c.1510) Museu de Belles Arts, Nimes. Oli sobre tela muntada en taula. $58 \mathrm{x} 42 \mathrm{~cm}$.

4 Per aprofundir més sobre els possibles retrats de Lucrècia, vegeu: Vigi (1981: 200-223).

5 De Hevesy (1932: 31). La veracitat d'aquesta còpia i la coherència que reproduís un retrat de Lucrècia Borja queda demostrada per una inscripció en el marc que indica el següent: Lucretia Borgia Alex. VI Pont. Filia «Alfonso Ferrar. Ducis Uxon». 
Alexandre Vico. Lucrècia Borja. L'alteració d'una identitat i l'errònia atribució de la pintura de Flora de Bartolomeo Veneto

En qualsevol cas, a més de les -exiguament esbossades- incògnites del primer retrat de Lucrècia pintat per Veneto i les diverses còpies posteriors, un dels problemes fonamentals a l'hora de donar resposta als interrogants sobre la identitat dels retrats, és intentar no confondre realitat i ficció. Els retrats amb voluntat mimètica respecte als individus representats, s'han d'interpretar d'una manera, i els retrats ideals acompanyats d'atributs o referències literàries s'han d'interpretar d'una altra. Aquest lleuger però taxatiu error és el que considero que van cometre historiadors com Hevesy en fonamentar les seves teories a partir d'una equívoca comparació entre els retrats demostrats de Lucrècia i altres obres de Veneto o d'altres artistes, que retrataven identitats ideals o al legòriques. Com emfatitza Burgess, no hem d'allunyar-nos dels retrats indubtables; com el de Nimes, el que Giovanni Antonio da Foligno hauria inclòs en els panells del reliquiari de Sant Maurelius, i, en definitiva, dels que -per evidències materials com inscripcions o altres- la unanimitat historiogràfica ha considerat que representen amb seguretat Lucrècia Borja (Burgess 2011). Llavors, hem de preguntar-nos ¿’per quina raó s’han produït i repetit tan sovint aquestes confusions?

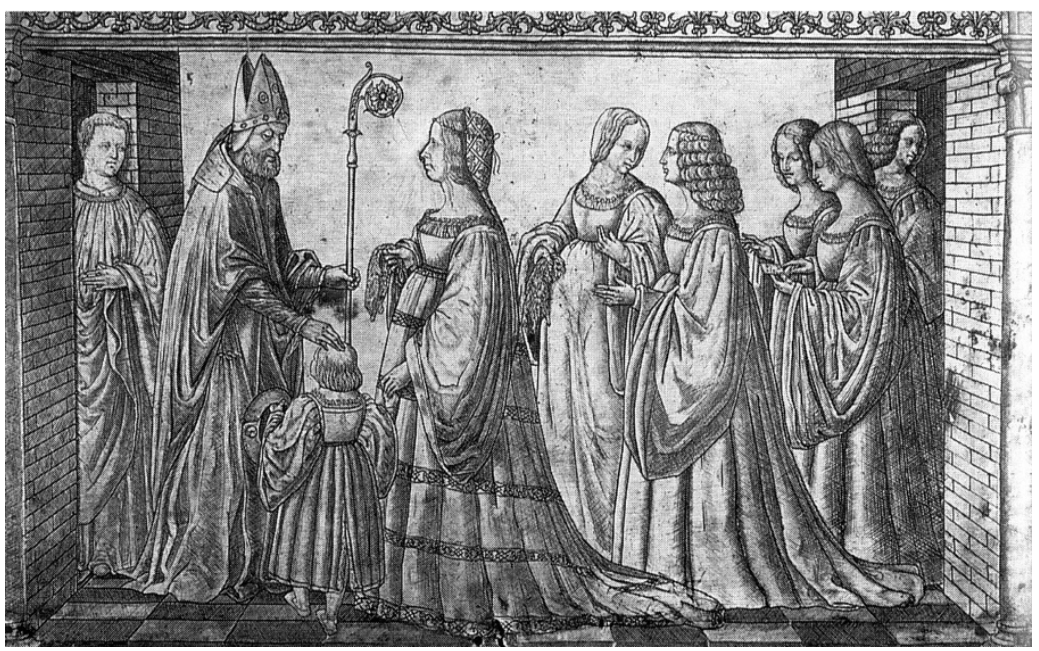

Giovanni da Foligno. Lucrècia com a duquessa de Ferrara amb el seu fill Ercole (c. 1514). Panell de reliquiari, Església San Giorgio fuori le mura, Ferrara. 
Alexandre Vico. Lucrècia Borja. L'alteració d'una identitat i l'errònia atribució de la pintura de Flora de Bartolomeo Veneto

\section{Lucrècia Borja i Flora, la concreció d'una identitat errònia}

Per donar resposta a la pregunta abans formulada, retornaré a l'objectiu principal d'aquestes dissertacions, amb què ja he insinuat que la pintura de Flora no s'ha de seguir interpretant com un retrat de la filla del Sant Pare. Com adverteix Pagnotta en relació a les propostes exegètiques del retrat, unes dècades després de les hipòtesis de Huysmans, Swarzenski o de Hevesy, va emergir una onada d'historiadors entre els quals destacaven Ingenhoff-Danhäuser, Ost, Lawner, Pedrocco, Tietzer, entre d'altres. Aquests estudiosos van advertir que el retrat de la deessa romana amb un posat tan incitant, més que desxifrar-se en relació a una identitat concreta, s'havia d'examinar comparant-lo amb les produccions pictòriques venecianes del seu temps. Tanmateix, proposaven que la Flora de Veneto coincidiria en especial amb una tipologia de retrats de cortesanes molt practicat per artistes com Giovanni Bellini, Giorgione, Tiziano, Tintoretto, Palma el Vell, etc. (Pozzi 1981, Pagnotta 1997). Tal corrent historiogràfica identificava múltiples retrats venecians com a representacions de prostitutes o amants d'homes que encarregarien les pintures, trets que en el cas de Flora explicarien la desinhibida actitud amb què la jove mostra el pit, llueix els auris cabells solts en senyal de solteria i mira directament a l'espectador.

Altres estudiosos com Burckhardt, Panofsky i Schaefer, van prestar especial atenció als atributs i elements iconogràfics complementaris com la corona de murta de Flora, oferint interpretacions simbòliques relacionades amb el myrtus coniugalis (Panofsky 1969), el valor de la castedat, la puresa confrontada amb la voluptuositat del pit exhibit, i, en definitiva, situant el retrat dins un context nupcial en què es transferien a l'esposa els caràcters d'una deessa (Gentili 1995). Així doncs, arribats al final del segle XX, ens trobem que d'una obra que pràcticament havia quedat oblidada després de la seva execució, quatre segles després es va produir una l'allau d'interpretacions ininterrompudes que van fer que la Flora de Veneto fos objecte de múltiples i heterogènies relectures: el dilema estava servit.

Resulta imprecís i complicat diferenciar fins a quin punt aquests retrats representen identitats concretes -siguin prostitutes, amants, esposes, etc.- 0 , per altra banda, personifiquen una sèrie valors morals expressats a través d'una representació completament ideal i prototípica. La nostra visió actual d'aquests aspectes resulta molt sovint anacrònica. Tenim l'errònia costum de classificar cada pintura dins un gènere concret. Però davant de casos com la Flora de Veneto, retrats venecians de principis del segle XVI -coneguts com el gènere de les belle donne- i moltes altres obres, hem de comprendre que el llindar entre el que avui considerem un retrat fidedigne i un retrat ideal no sempre es delimita amb claredat. De fet, un retrat sempre conté en sí mateix un valor d'idealisme, ja que per molt que un artista pretengui representar amb la màxima fidelitat un individu, tal retrat sempre serà un resultat subjectiu i fruit de la percepció d'altri. Així doncs, havent posat èmfasi en el factor experimental i arborescent del gènere del retrat durant el Renaixement, haurem de considerar una anàloga permeabilitat entre les manifestacions artístiques i les literàries. Com a reinterpretació i emulació de l'antiguitat que va caracteritzar el

SCRIPTA, Revista internacional de literatura i cultura medieval i moderna, núm. 9 / juny 2017 / pp. 286-311 ISSN: 2340 - 4841 doi:10.7203/SCRIPTA.9.10348 
Alexandre Vico. Lucrècia Borja. L'alteració d'una identitat i l'errònia atribució de la pintura de Flora de Bartolomeo Veneto

Renaixement, en el camp pictòric obté una especial embranzida l'ideal de l'ut pictura poesis, que alhora va donar pas a les representacions arquetípiques de bellesa femenina a partir del cànon petrarquista.

Aquest ideal exaltava trets físics com: els cabells rossos, pell clara, ulls brillants, celles arquejades, espatlles estretes, pits petits, etc., en síntesi, atributs que van configurar el model petrarquista de la donna angelicatta (Ferino-Pagden 2006). Com s'ha dit, tals trets físics i atributs d'arrel literària van resultar recurrents en els retrats especialment femenins de principi del segle XVI a la regió del Vèneto, però això no vol dir que fos un fenomen exclusiu i desconegut en els nuclis artístics de la resta d'Itàlia o Europa. Per posar un breu exemple amb relació al punyent desig d'individualitat renaixentista i la voluntat generalitzada -sobretot en sectors nobles- de fer-se representar a imatge i semblança de diferents personatges de l'antiguitat, és suficient amb girar la mirada a les produccions artístiques florentines de Benozzo Gozzoli, Sandro Botticelli o Filipinno Lippi a través dels quals la família Medici es feia representar ni més ni menys que sota la identitat dels Reis Mags. D’un pintor proper, Domenico Ghirlandaio ${ }^{6}$, també en destaquen precisament produccions pictòriques per a la nissaga dels Tornabuoni, en què personalitats femenines com Giovanna Tornabuoni adoptaven l'aspecte de personatges bíblics com a motiu apotropaic i de redempció espiritual (Van der Sman 2010: 107 i ss.).

Personatges de l'Antic i Nou Testament, déus pagans, herois mítics, literaris, etc., conformaven un ventall iconogràfic a través del qual els individus poderosos es presentaven i n'adquirien els corresponents valors: sacres, llegendaris, morals, al legòrics, etc. Sovint els comitents escollien determinats temes buscant la protecció dels sants o personatges homònims. Produccions pictòriques finiseculars directament relacionades amb la família Borja -com són els frescos realitzats per Pinturicchio al Palau Apostòlic Vaticà- també fan ús d'aquesta reeixida fórmula de transferència de valors, donant com resultat una controvertida representació de Santa Caterina d'Alexandria sovint considerada un retrat ideal de Lucrècia Borja a causa de diferents paral lelismes (Martínez García \& Vázquez de Ágredos Pascual 2016).

6 Domenico di Tommaso Curradi di Doffo Bigordi (Florència, 1449-1494), més conegut pel malnom «Ghirlandaio»: 
Alexandre Vico. Lucrècia Borja. L'alteració d'una identitat i l'errònia atribució de la pintura de Flora de Bartolomeo Veneto

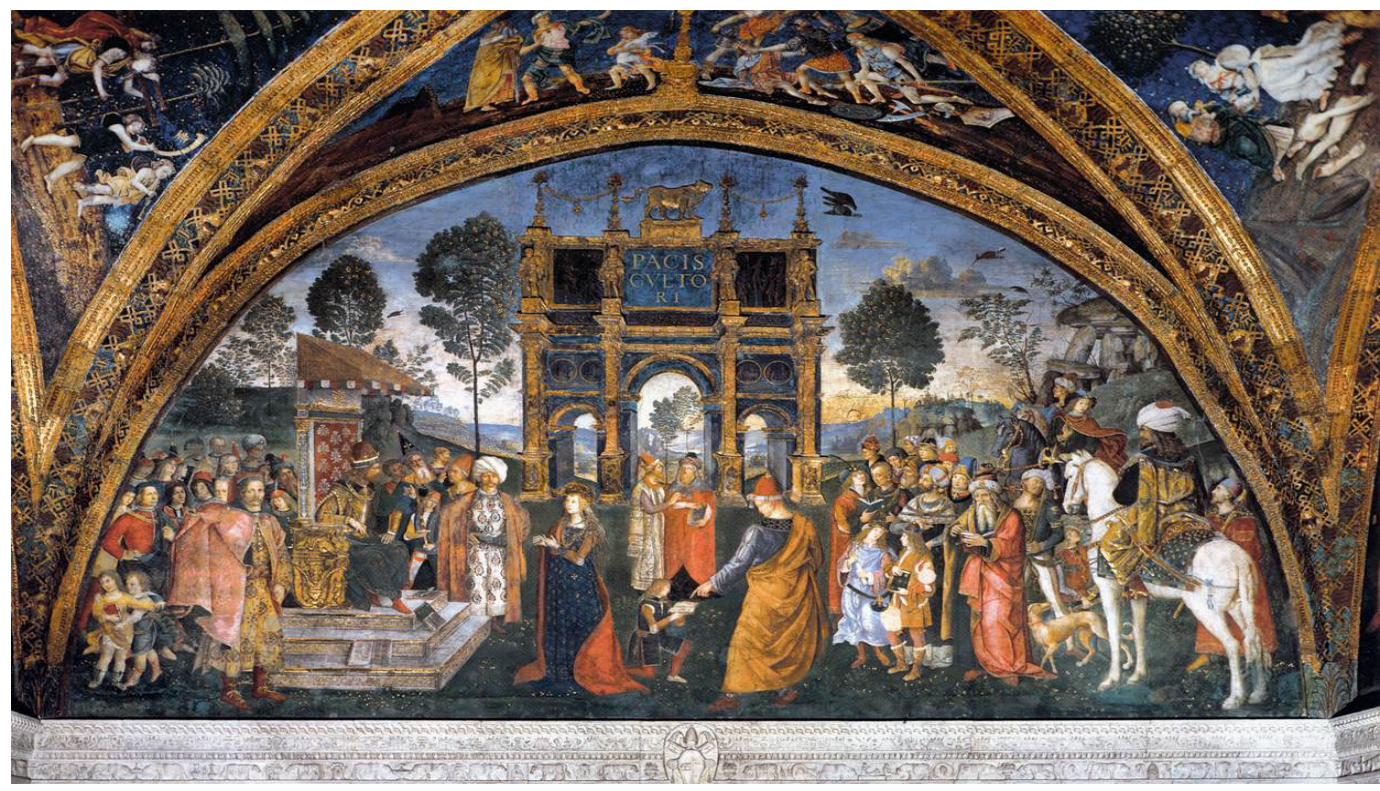

Pinturicchio, Disputa de Santa Caterina d'Alexandria (c. 1494). Sala dels Sants, Apartaments Borja del Palau Apostòlic Vaticà, Roma.

De manera que, per acostar-nos a una més aproximada interpretació de la Flora de Veneto, per una banda hem de tenir en compte aquests condicionants estètics compartits, i per altra banda, considero que hem d'emprar els mateixos mecanismes d'exegesi que en altres obres de l'entorn venecià, com poden ser la Laura (1506) de Giorgione, la Flora de Tiziano (1515-1517), La Bella (1518-1520) de Palma el Vell, etc.; és a dir, comprendre el seu caràcter ambivalent i llegir-les en clau metartística, especialment literària. Les obres mencionades no només coincideixen amb les representacions florentines prèvies per «disfressar» els personatges retratats, sinó que a més són pintures de polaritats. Igual que succeeix amb la Flora de Veneto en què tenim per una banda mitologia i sensualitat, són retrats femenins que representen valors - a priori- oposats. ${ }^{7}$ Molt sovint transcriurien conceptes presents a fites literàries clàssiques com les Metamorfosis d'Ovidi, o bé estarien influïts per les manifestacions poètiques coetànies, etc.

\footnotetext{
7 Amb relació a aquesta polaritat, cal destacar altres interpretacions que consideren que el penjoll que porta Flora, deessa de la renovació estacional, representa una creu al lusiva a Crist i el seu sacrifici anàleg com a valor de renovació. Ferguson (1955: 31-32) i Levi D’Ancona (1977: 124-126).
} 
Alexandre Vico. Lucrècia Borja. L'alteració d'una identitat i l'errònia atribució de la pintura de Flora de Bartolomeo Veneto
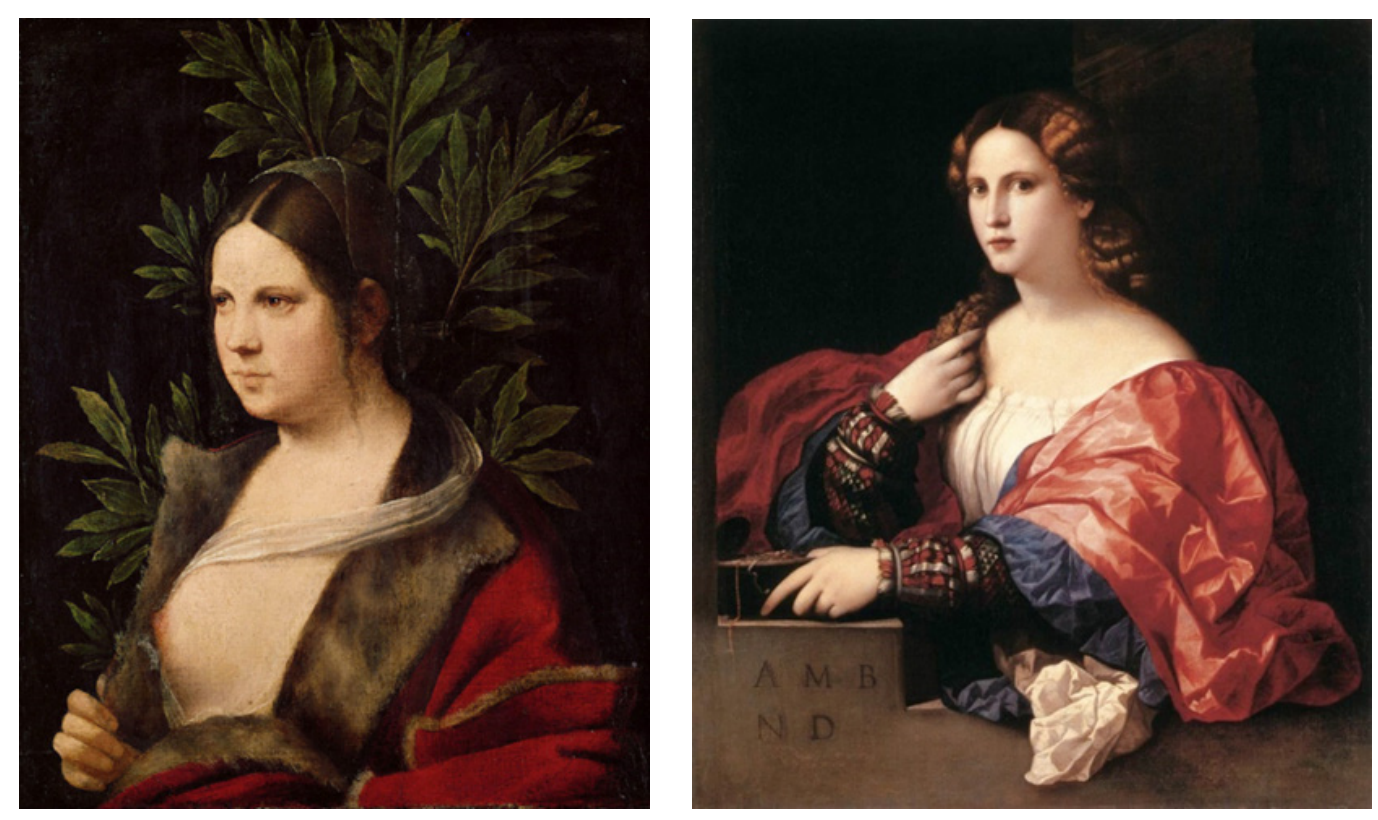

Giorgione, Laura (1506). Kunsthistorisches Museum, Viena. Palma el Vell, Retrat de dona anomenat «La Bella» (1518-1520). Museu Thyssen-Bornemisza, Madrid.

Novament, la contrastació d'aquest gènere pictòric de gran èxit a Venècia en relació amb les pintures florentines del mateix període cinccentista ens porta a unes mateixes conclusions entre dos medis artístics que -tot i parangonar els principis artístics del color o el disegno- compartien experiències i desenvolupaven certs aspectes al mateix temps. Un retrat femení d'Andrea del Sarto (c.1528) no deixa dubte de l'ús del retrat florentí des d'una lectura també en clau poètica, ja que en aquest cas es representen directament els sonets de Petrarca entre les mans de la retratada. Un altre exemple conservat també a la Galleria degli Uffizi de Florència -en aquest cas pintat per Agnolo Bronzinopresenta Lucrezia Panciatichi (c.1541) amb un llibre obert en què es poden reconèixer versos del Càntic dels Càntics. L'elecció d'aquesta font bíblica va ser realitzada volgudament pel marit de la retratada amb la pretensió d'al ludir a la intensitat sentimental que aquest sentia per la seva esposa.

Així doncs, amb aquests exemples i molts més, podem advertir, d'una banda, la continuïtat que la tradició pictòrica del segle XVI seguia respecte a un corpus bíblic o literari apreciat especialment durant el Quattrocento, i d'altra banda, com aquestes referències literàries cada cop eren transcrites de manera més implícita o explícita mitjançant la sofisticada forma d'expressió del retrat. 

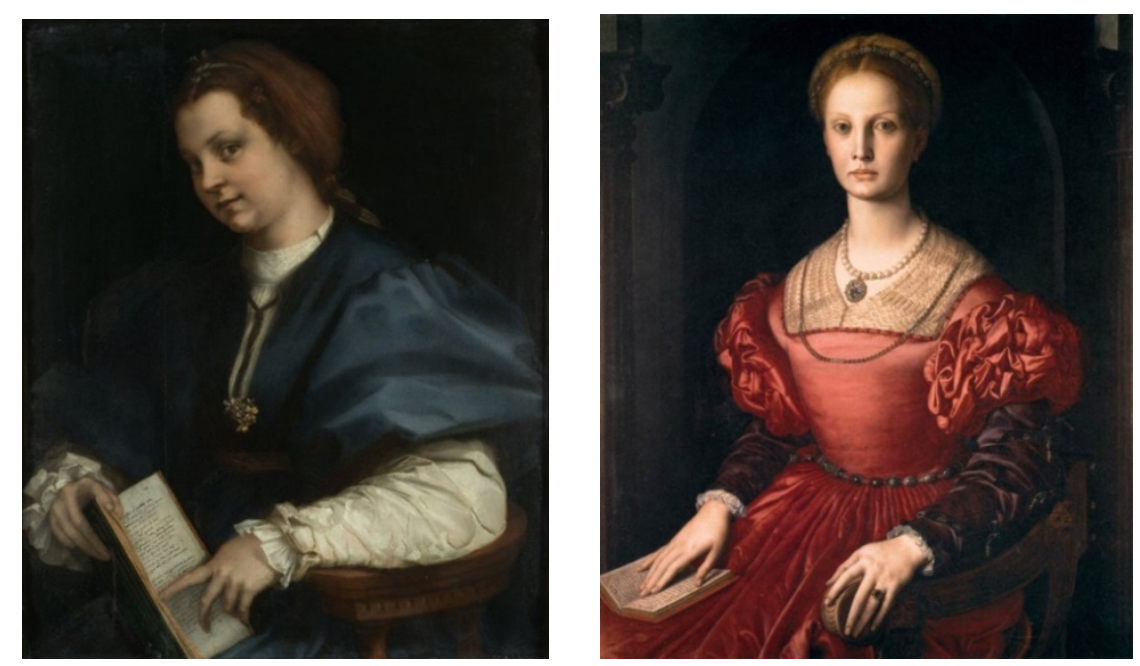

Andrea del Sarto. Dama col Petrarchino (1528). Galleria degli Uffizi. Agnolo Bronzino. Retrat de Lucrezia

Panciatichi (1541). Galleria degli Uffizi.

Més enllà dels seus continguts formals, la pintura no només transcriu els ideals de la poesia, sinó que hi parangona per tal d'erigir-se com a hegemònica transmissora del paradigma estètic de la bellesa sense necessitat de context narratiu. En alguns casos, les retratades encarnaven virtuts de puresa al lusives a la Verge Maria però alhora no deixaven de lluir una sensual galanteria, que es mostrava en aquells moments com un valor compatible. El retrat, doncs, admet una multiplicitat de lectures no excloents, transcriu els ideals poètics tot mantenint un antagònic equilibri entre la representació física exterior i el reflex interior de la bellesa de l’ànima (Cropper 1976, Falomir 2008: 306). Després dels arguments presentats a mode de bagatge artístic amb relació al context pictòric de la primera meitat del segle XVI, sembla sensat interpretar la Flora de Veneto des dels paràmetres artístics venecians ressaltats i veure-hi la influència poètica tant de Francesco Petrarca com Pietro Bembo, que justament integrava la cort de Lucrècia Borja a Ferrara. Durant els anys que l'esmentada duquessa va viure a la cort, es va produir un notable desenvolupament de la poesia que va deixar una especial empremta en la posteritat. A principis del segle XVI, Ferrara va viure el seu apogeu; demogràficament devia ésser més populosa que Roma i era una ciutat pròspera en diversos aspectes. Culturalment, la noblesa també buscava emmirallar-se en l'antiguitat grecollatina, i, segons algunes fonts, sabem que no només de camí a Ferrara Lucrècia Borja va ser rebuda arreu dels pobles amb carruatges triomfals com si fos una deessa digne de participar en el judici de Paris, sinó que fins i tot el seu fill Ercole, la comparava a Juno per les obres de caritat, amb Pal les pels costums, i amb Venus per la semblança (Gregorovius 2007: 155, 309). S'ha indicat que molts monarques i individus nobles cada cop més es feien retratar amb atributs d'herois mítics, déus pagans, sants, etc., però -més enllà de les analogies i mecanismes de prestigi, de devoció, etc.- considero que és un error relacionar la fesomia de la sensual Flora amb la identitat de Lucrècia Borja. 
Alexandre Vico. Lucrècia Borja. L'alteració d'una identitat i l'errònia atribució de la pintura de Flora de Bartolomeo Veneto

\section{Interpretacions més plausibles}

Lluny de qualsevol semblança física amb la duquessa com podrien ser els elogiats cabells auris de Lucrècia Borja ${ }^{8}$ i el pentinat que també apareix a les medalles, el retrat de Flora respondria a múltiples exegesis. Primerament, no s'ha d'oblidar que la pintura és un suport de memòria, com deia Leon Battista Alberti «capaç de fer presents als absents» (Sinisgalli 2011: 44). De trobar algun indici o prova fefaent -fins el moment inexistent- que indiqués que Veneto va pintar aquesta obra mentre era a Ferrara, podríem considerar que la comitència buscava satisfer una voluntat commemorativa -en forma de personificació al legòrica-, per exemple, del clima pretèrit tan ufanós i fèrtil intel lectualment que es respirava a la cort de Ferrara mentre Lucrècia era viva; retratant un tempus fugit de joventut emocional sublimat en la representació de l'exuberant deessa. En la mateixa línia d'aquest valor de prosperitat relacionat amb aquesta deïtat, algunes propostes recents veuen també la Flora de Veneto com l'emblema del floriment de la nova estació cultural i artística que va tenir lloc a Venècia durant els últims anys del segle XV i primers anys del segle XVI, moment en què Aldo Manuzio9 encara era actiu com a estampador, i es van publicar les Rime de Petrarca, les obres de Dante, Giovanni Pontano, Jacopo Sannazaro, i un llarg etcètera d'exemplars rellevants de la literatura europea (Aldo Manuzio. Renaissance in Venice 2016). Aquestes dues hipòtesis -la primera com a representació de l'abundància produïda a Ferrara per la presència de Lucrècia Borja, i la segona com a progrés també de la cultura literària italiana en què destaca la figura de Manuzio-, són interpretacions interessants i que mereixen mencionar-se a causa de l'existència de retrats en què es personifiquen ciutats, esdeveniments històrics, etc.

No obstant això, com s’ha indicat en línies anteriors, la interpretació més aproximada -tenint en compte les coincidents característiques amb el gènere del retrat venecià- serà comprendre l'obra de Veneto com un manifest estètic d'arrel literària estimulat per l'influx produït per Bembo i les fonts neoplatòniques; com una icona que sintetitza les múltiples facetes i valors morals antitètics atorgats al rol femení aristocràtic. El pes literari venecià i una lectura-com les més acceptadesde Flora en clau poètica inevitablement acosta aquesta pintura als ideals establerts per Bembo al diàleg amorós Gli Asolani, dedicat precisament a Lucrècia Borja a principis del segle XVI i en què s'estableix la mateixa dualitat amb relació a les nòvies o esposes que eren considerades castes i alhora objecte de desig sexual. Cal recordar que també Giovanni Pontano va elogiar en el seu De fulgentissimis Lucillae papillis ${ }^{10}$ les virtuts femenines, entre les quals destaca especialment aquell

\footnotetext{
8 Sovint s'ha proposat que es tenyís els cabells, costum practicada a l'època. Per aprofundir més sobre diverses descripcions físiques de Lucrècia Borja vegeus: Gregorovius (1975: 166-167.), Menotti (1992: 198-199), Gomar (2016).

9 Se’l coneixia com Aldo Manuzio o en la forma llatina Aldus Pius Manutius, però el seu nom era Teobaldo Mannucci (Bassiano 1449- Venècia 1515).
}

10 Localitzable al Ioannis Iovani Pontanis Carmina editat al 1505, després de la seva mort.

SCRIPTA, Revista internacional de literatura i cultura medieval i moderna, núm. 9 / juny 2017 / pp. 286-311 ISSN: 2340 - 4841 doi:10.7203/SCRIPTA.9.10348 
cant a l'esplendor que suscita el pit de Lucila. De fet, l'exhibició d'un pit no només s'entén com un tret atribuïble únicament a la deessa Flora, sinó que esdevé una metàfora del nodriment de la vida, la seducció i la virtut interior. Segons el context, un pit nu pot simbolitzar diferents valors, contraris fins i tot entre ells. Pot entendre's com un element de distinció entre els animals i les relacions amoroses humanes, com un tret distintiu de les verges vestals romanes o la mateixa Lucrècia -heroïna de la fidelitat conjugal i homònima de la duquessa Borja ${ }^{11}$-, o bé com l'exaltació del vincle entre una mare $i$ un fill, i que en el context cristià trobaria la seva màxima expressió en la representació de la Verge alletant el Nen (Dal Pozzolo 2008: 43). Si seguim desgranant els simbolismes i les formes de representació de la Flora de Veneto, tampoc no podem passar per alt una duplicitat simbòlica inherent a aquest deessa. ${ }^{12}$ D'una banda, la representació de Flora pot exaltar el valor de la castedat i el triomf conjugal com a Flora primavera esposa de Zèfir que llueix la murta advertida pels estudis iconològics, i d'altra banda, l'exhibició d'un pit la situa en la forma anomenada Flora meretrix, és a dir, al ludint a la part més mundana i sensual en què la teoria mitològica considerava que Flora era en un primer moment una prostituta divinitzada pel seu caràcter generós. A més, una possible hipòtesi derivada d'aquesta lectura és que tal polaritat de formes de la Flora casta i al mateix temps prostituta esdevé una idea certament extrapolable a la identitat de Lucrècia Borja. La correspondència entre ambdues seria conceptual i no formal, és clar. La deessa romana compartiria amb Lucrècia el tractament difamant tacat de connotacions sexuals -que en el cas dels Borja provindria dels calumniadors de Roma- i alhora de les dues se n'encomiaven els valors de la castedat i puresa -que per Lucrècia tindrien la seva correspondència en el pietós món ferrarès. Aquesta interpretació trobaria un mínim suport perquè, -encara que la pintura se sol datar en anys propers a la mort de Lucrècia-, de mantenir una relació simbòlica directament amb aquesta, el missatge simbòlic de la pintura correspondria a un receptor -o qui sap si comitent- d'elevat nivell cultural i formació clàssica com era la duquessa. Com s'ha dit, el fervor del gènere del retrat era imparable a mitjans del segle XVI, i la transferència d'identitats bíbliques, divines, literàries, etc., per part de comitents aristòcrates no era quelcom exclusiu o extremadament agosarat. Sigui com sigui, l'interessant contrast entre feminitat casta i pura respecte al vessant més sexual i cortesà, esdevé una fórmula compositiva de fortuna i repetida per retratistes tan originals com Arcimboldo. Les seves teste composte de Flora $i$ Flora meretrix evidencien aquest valor de pendant que en el cas de Bartolomeo Veneto considero que podria sintetitzar-se en l'única però ambivalent Flora.

11 Aquesta simbòlica correspondència permetria relacionar la identitat del personatge Lucrècia de la història romana -caracteritzada per ser violada per Sextus Tarquinius- amb la casta Lucrècia Borja i el seu virtuós modus vivendi ferrarès. Malgrat aquesta possibilitat, per diferents motius que a continuació s'exposaran -fonamentalment formals i recurrents en l'estil figuratiu de Bartolomeo Veneto- resulta més adient allunyar la identitat al legòrica de la pintura Flora de Lucrècia Borja.

12 Amb relació a les múltiples iconografies de la deessa Flora vegeu: Held (1961) i Shteir (2006: 3-27). 

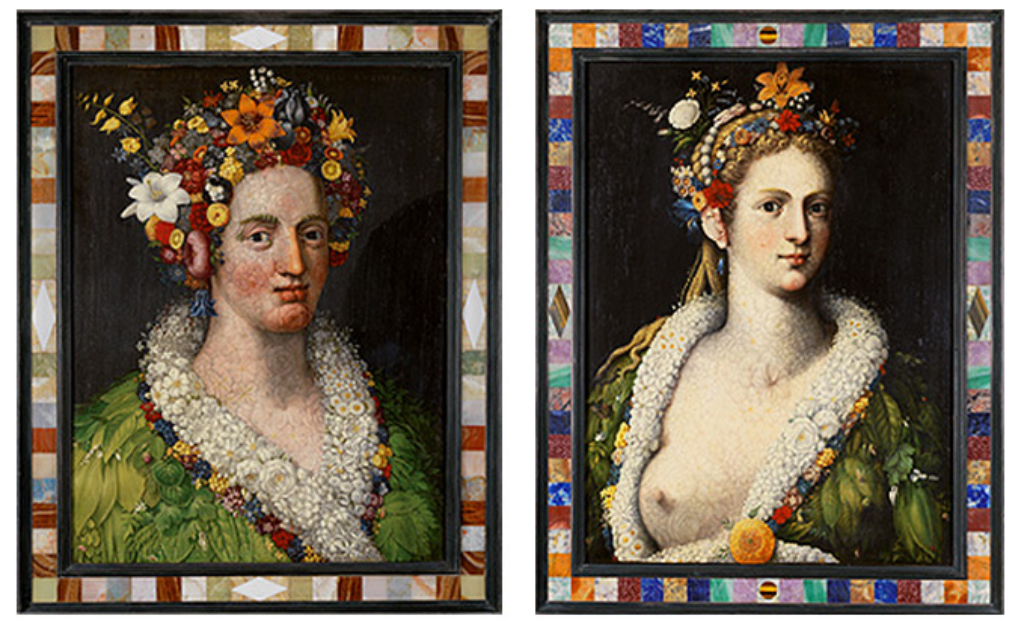

Giuseppe Arcimboldo. Flora i Flora meretrix (1589 i c.1590). Col lecció particular.

Fent un concís parèntesi per comprendre la recepció i impressió que hauria produit una pintura tan explícita com la Flora de Veneto, cal reincidir en el fet que la seva datació i el seu estil són incerts. Per a alguns se situa a la primera dècada del segle XVI i, per a altres oscil la pels volts de la dècada de 1520. En conseqüència, aquesta incògnita obre el debat afegit sobre si Bartolomeo Veneto va pintar la Flora mentre s'estava a Ferrara, l'havia pintat abans a Venècia o en un altre lloc temps després. En qualsevol cas, per valorar la seva possible inserció dins el nucli cortesà de Ferrara, ens resulten molt il lustratius els comentaris de Giorgio Vasari respecte a alguns pintors venecians. Tot i que s'ha dit que l'escriptor aretí no va dedicar a Veneto cap espai en les Vite d'il lustres artistes, sí que ho va fer amb Tiziano, del qual obtenim valuoses informacions que podem aplicar a l'autor de Flora. Quan Vasari descriu la vida i obra de Tiziano ${ }^{13}$, informa que el duc de Ferrara Alfons I d'Este, l'any 1514 va encarregar a Dosso Dossi ${ }^{14}$ decorar una sala i diversos compartiments amb històries d'Enees, Mart, Venus, Vulcà, etc. Fins i tot, sabem de l'admiració que Alfons I d'Este professava per artistes venecians com Giovanni Bellini, el qual va realitzar per a ell una pintura de gran format amb figures bacants, músics, sàtirs, etc., que a la seva mort va finalitzar Tiziano (Vasari 1881: 433). Aquests valuosos comentaris ens indiquen quina era la consideració que tenien determinats artistes a la Ferrara de l'inici del segle XVI, i tanmateix permeten comprendre quina era la demanda artística més privada -destinada en aquest cas a l'embelliment de l'anomenat «camerino d'alabastre» del castell dels Este- que el marit de Lucrècia va encarregar pocs anys abans que aquesta morís. Tot i desconèixer la ubicació on Veneto va realitzar la pintura de Flora, el testimoni vasarià permet

13 Tiziano Vecellio (Pieve di Cadore c. 1485/1490 - Venècia 1576).

14 Precisament a Giovanni di Niccolò Luteri (San Giovanni del Dosso c. 1490 - 1542), -més conegut com Dosso Dossi- també s'atribueix un retrat relacionat amb Lucrècia Borja amb data propera a $1516 \mathrm{i}$ actualment conservat a la National Gallery of Victoria de Melbourne. 
Alexandre Vico. Lucrècia Borja. L'alteració d'una identitat i l'errònia atribució de la pintura de Flora de Bartolomeo Veneto

admetre una factible recepció d'aquesta pintura -juntament amb la resta de temàtiques mitològiques i al legòriques de Dossi, Bellini, etc.- dins l'ambient ferrarès. Tant per l'exegesi que obtenim dels continguts al legòrics que representa Flora, com per l'alta qualitat de la pintura i la reiterada relació de Bartolomeo Veneto amb un nucli tan exigent com la cort de Ferrara, podem considerar que la comitència d'una obra com aquesta no hauria d'estar massa lluny de figures cabdals com Lucrècia Borja o Alfons d'Este.

\section{Conclusions}

Tot i les múltiples accepcions de la pintura de Flora i la limitada recepció que hauria tingut, insisteixo que no hem de caure en l'error de veure en Flora un reflex físic o directe de la duquessa i menys que fos quelcom identificable pels altres espectadors. Tal i com ens indiquen alguns estudis iconogràfics amb relació a la família Borja, el modus vivendi de Lucrècia a la cort ferraresa era cada cop més discret -quasi monacal- $\mathrm{i}$ allunyat de les modes femenines que convidaven a lluir vestits escotats (Menotti 1992: 198). Sabem que en una data propera al 1513, el seu fervor religiós la va portar a consagrar-se a la devoció, a fundar convents i hospitals; fins i tot, davant les dificultats econòmiques i polítiques per les quals passava Ferrara no va dubtar a empenyorar les seves joies i renunciar a tota la pompa i vanitat a la que estava habituada des de jove (Gregorovius 2007: 333). Tals conductes resulten contràries a l'exaltació del luxe i la bellesa fugissera que proclama la pintura de Veneto; una representació volgudament eròtica on preval especialment la forma meretrix de Flora. Encara que també resulta temptador vincular-la a les coetànies escenes de toilette i de dones pentinant-se -o mirant-se al mirall- que acostumava a pintar Giovanni Bellini, és evident que la Flora de Veneto no és captada per sorpresa. Tampoc la veiem parcialment des de la posició d'un voyeur, sinó que ella se'ns presenta de cara interpel lant-nos directament. De ben segur que la percepció suscitada al segle XVI va ser molt més intensa i suggestiva del que avui dia -que tenim una cultura visual molt més nodrida- podem creure. No només la sensualitat, la nuesa i la insinuació al plaer sexual -simbolitzada per les flors- de la mater florum serien valors massa gratuïts per transferir-se al que s'entendria com un retrat fidedigne de Lucrècia. Els últims estudis descarten que Veneto manifestés en la representació de Flora aparents intencions retratístiques o mimètiques de qualsevol dona real. S'esvaeix la possibilitat d'identificar aquells trets físics de la jove que havien arribat a la posteritat i que alguns estudiosos creien localitzar en els diversos hipotètics retrats de Lucrècia.

Com coherentment enfoca Laura Pagnotta, Bartolomeo Veneto va emprar per al model de Flora el mateix rostre ideal utilitzat durant els anys propers per crear diverses de les seves madonne. De la mateixa manera que succeïa amb molts altres artistes del Renaixement -com per exemple Sandro Botticelli, Leonardo, etc.-, Veneto va fer ús d'una manera evident uns models ideals que tant podien aplicar-se a usos profans com religiosos. La innegable semblança entre Flora i una de les madonne del mateix pintor- com és la que es conserva a la Levinson Collection- esvaeix qualsevol dubte sobre

SCRIPTA, Revista internacional de literatura i cultura medieval i moderna, núm. 9 / juny 2017 / pp. 286-311 ISSN: 2340 - 4841 doi:10.7203/SCRIPTA.9.10348 
Alexandre Vico. Lucrècia Borja. L'alteració d'una identitat i l'errònia atribució de la pintura de Flora de Bartolomeo Veneto

aquesta pràctica. Segons l'esmentada experta en Bartolomeo Veneto, aquesta evident utilització de fórmules figuratives ambivalents seria un motiu suficient per excloure la categorització de l'obra com un retrat concret o identificable (Pagnotta 1997).
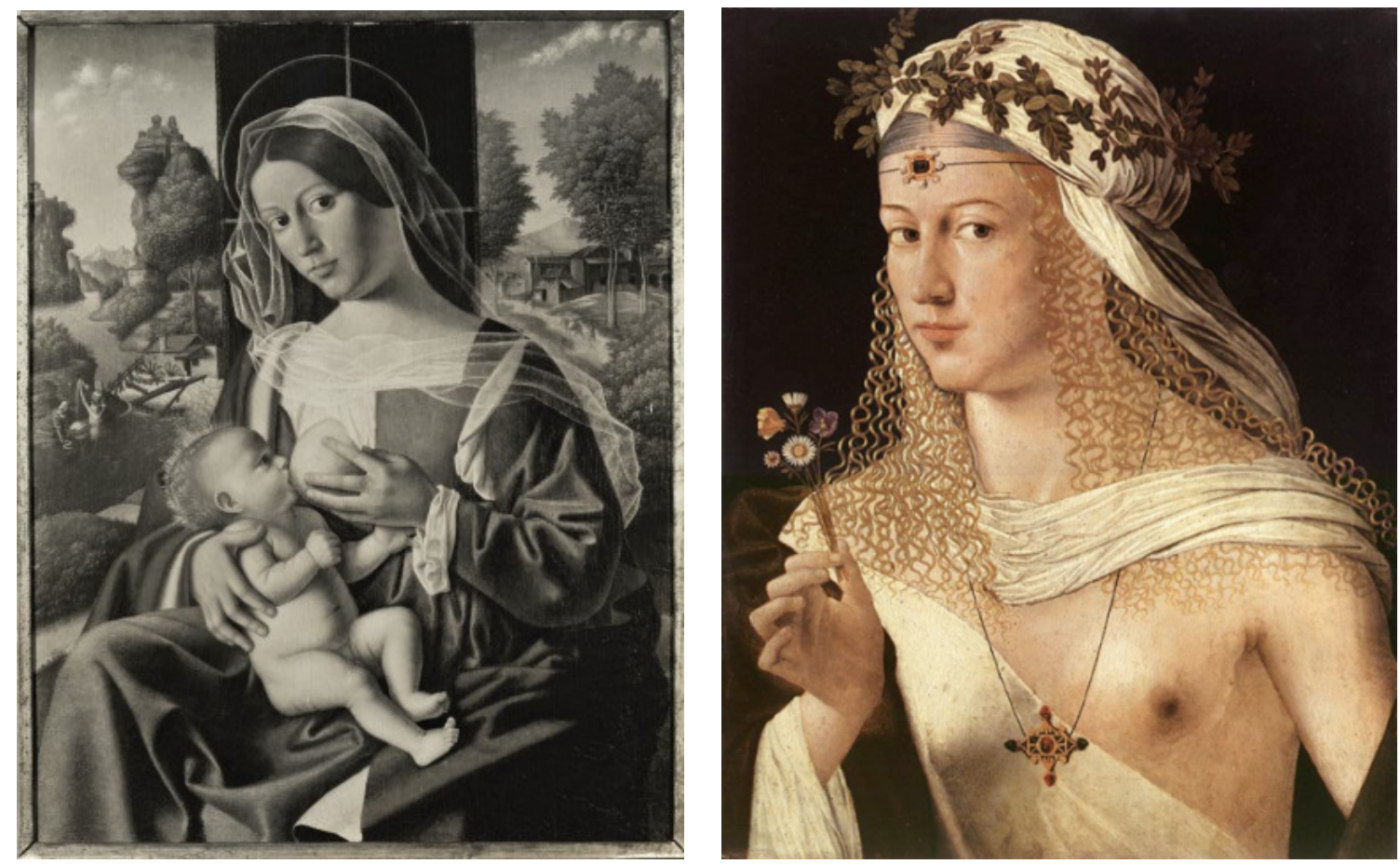

Bartolomeo Veneto. Madonna alletant al Nen (c. 1508). Levinson Collection, Seattle. Bartolomeo Veneto.

Flora (c. 1520). Städelsches Kunstinstitut, Frankfurt.

Així doncs, havent exposat sintèticament els valors que representa la Flora de Veneto i per quins motius s'ha d'interpretar com una personificació ideal i no un retrat de Lucrècia Borja, considero que poc més s'ha d'afegir per respondre a la pregunta que inicialment es plantejava sobre, per què aquest retrat ha causat tanta contrarietat i s'ha relacionat amb tanta freqüència amb Lucrècia. Precisament ha estat la concordança de valors -que tant la pintura com la posterior fama de Lucrècia han compartit-, el principal punt d'adhesió entre pintura i identitat. La provocadora actitud amb què la pintura ens mira està en perfecte sintonia amb les falsejades etiquetes que s'han anat sumant a la consideració de Lucrècia. Les crítiques a la família Borja han estat continuades durant els segles, la qual cosa feia previsible que d'una manera o altra es busqués posar imatge a cadascun dels seus membres. La comparació amb l'obra de Pol Coronado ens ha permès conèixer quina és la visió que gran part de la societat de l'any 2016 té de Lucrècia Borja. Penso que, si no hagués estat com ha succeit en l'equivocada assignació de la identitat de Lucrècia a la pintura de Flora de Bartolomeo Veneto, d'alguna altra manera s'hauria buscat una manifestació artística que pogués 
representar -per exemple- el rostre de Cèsar Borja sota l'aparença d'algun personatge maligne d'un episodi mitològic, religiós o quelcom semblant. Si a l'afany de denigració cap els Borja sumem el desconeixement produït per la manca d'uns mecanismes de lectura i interpretació correctes de les obres o retrats -que en aquest cas han demostrat àmpliament ser representacions més ideals que mimètiques-, el resultat és una associació pràcticament automàtica. La Flora de Veneto suposa un dels casos més flagrants d'aquesta manipulada caracterització d'uns trets o valors morals que ràpidament van trobar reflex en la desvirtuada identitat de Lucrècia Borja, així com també se l'hauria pogut relacionar amb altres personatges de connotació eròtica com la deessa Venus -o en forma romana Afrodita-, mènades, nimfes, etc. La qüestió és que el que va sorgir com una crítica en el seu moment principalment per contrarestar el poder i posició dels Borja no s’ha diluit amb el pas del temps. Progressivament, per fascinació, falses creences, etc., la imatge projectada pels detractors d'aquesta família s'ha perpetuat i no ha cessat d'estimular tota mena de productes literaris, musicals, teatrals, pictòrics, cinematogràfics, etc., centrats en la seva «llegenda negra». Tan fructífera ha esdevingut aquesta fama, progressivament deformada i magnificada pel vel de la ficció, que s'ha de reconèixer que des del final del segle XV ha contribuït a universalitzar un record que ha permès no oblidar -encara que sigui pejorativament- la família Borja. La pintura de Bartolomeo Veneto i la seva inseparable lectura amb relació a la identitat de Lucrècia pot entendre's com el paradigma visual d'aquesta foscor i desconeixement que ha acompanyat aquesta nissaga.

Com s'ha adduït al llarg d'aquestes breus pàgines, l'icònic retrat de Flora supera l'exegesi d'un retrat amb una única voluntat mimètica. El rostre modèlic i indeterminat emprat per Veneto l'allunya d'aquest sentit fidedigne i representatiu que aparentment correspon a la pròpia raison d'être del gènere del retrat. De quedar-nos amb una lectura superficial de l'obra, no arribaríem a copsar tot el que representa: un testimoni plàstic que ens apropa als ideals d'una cultura refinada que s'emmiralla en l'antiguitat, una conflictiva representació que ens permet albirar la canviant concepció de les dones al segle XVI, una transcripció visual del fervor poètic encapçalat per Bembo, etc. Recordant les impressions generades en un acte convenient i reivindicatiu com el que es va celebrar a Xàtiva, cada cop som més els que esperem que, en aquests temps de revisió històrica i rigor intel lectual, caiguin pel seu propi pes les abusives fal làcies per seguir aportant certeses i recuperar la veritable història dels Borja. 
Alexandre Vico. Lucrècia Borja. L'alteració d'una identitat i l'errònia atribució de la pintura de Flora de Bartolomeo Veneto

\section{Bibliografia}

Aldo Manuz̧io. Renaissance in Venice (2016), Catàleg d'exposició, Gallerie dell'Accademia, Venècia, Marsilio.

Bellonci, Maria (2003) Lucreżia Borgia, Milà, Arnoldo Mondadori Editore.

Berenson, Bernard (1916) Venetian Painting in America: The fifteenth century, Nova York, Sherman.

Burgess, Allyson (2012) «Rewriting Lucrezia Borgia: Propierty, Magnificence, and Piety in Portraits of a Renaissance Duchess» dins Katherine McIver (ed.) Wives, Widows, Mistresses, and Nuns in Early Modern Italy, Making the Invisible Visible through Art and Patronage, Farnham, Ashgate Publishing, pp. 77-97.

Cropper, Elizabeth (1976) «On beautiful Women, Parmigianino, Petrarchismo, and the Vernacular style», Art Bulletin, no 58, pp. 374-394.

Dal Pozzolo, Enrico Maria (2008) Colori d'Amore, Parole, gesti e carezze nella pittura veneziana del Cinqueccento, Treviso, Edizioni Canova.

De Hevesy, André (1932) «Some portraits of the Borgias-Lucrezia», The Burlington Magazine for Connoisseurs, Vol. 61, nº 352, pp. 21-31.

Falomir, Miguel (2008) El retrato del Renacimiento, Madrid, Museo Nacional del Prado.

Ferguson, George (1955) Sign and Symbols in Christian Art, Londres, Oxford University Press.

Ferino-Padgen, Sylvia (2006) «Palma Vecchio. Potrait of a Woman («La Bella»)» dins Brown D.A. / Ferino-Padgen S. / Anderson J. (eds.) Bellini, Giorgione, Titian and the Renaissance of Venetian Painting, Washington D.C - Viena, National Gallery of Art - Kunsthistorisches Musem, pp. 230-231.

Fioravanti Baraldi, Anna Maria (2002) Lucrezia Borgia: la beltà, la virtù, la fama onesta, Ferrara, Gabriele Corbo Editore.

Francescini, Adriano (1997) Artisti a Ferrara in età umanistica e rinascimentale. Testimonianze archiviste, parte II, Vol. II, Ferrara, Gabriele Corbo Editore.

Gentili, Augusto (1995) «Amore e amorose persone: tra miti ovidiani, allegrie musicali, celebrazioni matrimoniali», dins Tiz̨iano. Amor Sacro e Amor Profano, catàleg d'exposició, Milà, Electa, pp. 82105.

Gilbert, William (1869) Lucrezia Borgia, duchess of Ferrara. A biography, Vol. II, Londres, Hurst and Blackett Publishers.

Gomar, Marc (2016) «Lucrècia Borja: més enllà dels pinzells» dins Revista Borja. Revista de l'Institut Internacional d'Estudis Borgians (IIEB), 5, Actes del Congrés Els Borja en l'art, pp. 1-22.

Gofen, Rona (1997) Titian's Women, New-Haven i Londres, Yale University Press.

Gregorovius, Ferdinand (1975) Lucrecia Borgia, Gènova, Editions Ferni.

—_. (2007) Lucrècia Borja a partir de documents i epistolaris del seu temps, Institut Internacional d'Estudis 
Alexandre Vico. Lucrècia Borja. L'alteració d'una identitat i l'errònia atribució de la pintura de Flora de Bartolomeo Veneto

Borgians (Biblioteca Borja, 4), València, Tres i Quatre.

Held, Julius (1961) «Flora, Goddess and Cortesan» dins Millard Meiss (ed.) Essays in Honor of Erwin Panofsky, Nova York, New York University Press, Vol. I, pp. 201-218 i Vol. II, pp. 69-74.

Huysmans, Karl (1905) Trois Primitifs. Les Grünewald du Musée de Colmar. La Maître de Flemalle et la Florentine du Musée de Francfort-sur-le-Main, París, Vanier.

Koshikawa, Michiaki (2009) L'Arte Erotica del Rinascimento, Tòquio, The National Museum of Western Art / The Yomiuri Shimbun.

Laureati, Laura, Lucręia Borgia (2002), Catáleg d'exposició, Palazzo Bonacossi, Ferrara Arte.

Les Borgia et leur temps: De Léonard de Vinci à Michel-Ange (2014), Catàleg d'exposició, Musée Maillol, Gallimard.

Levi D'Ancona, Mirella (1977) The Garden of the Renaissance, Botanical Symbolism in Italian Painting, Florència, Leo S. Olschki.

Martínez García, Ma Julia \& Vázquez de Ágredos Pascual, Ma Luisa (2016) «Tradición y renovación en la imagen de Lucrecia Borgia: un anàlisis desde las fuentes visuales» dins Revista Borja. Revista de l'Institut Internacional d'Estudis Borgians (IIEB), 5, Actes del Congrés Els Borja en l'art, pp. 1-27.

Menotti, Mario (1992) Els Borja, a cura de M. Batllori, Marià Carbonell i Ximo Company, València, Bancaixa.

Mira, Joan Francesc (2000) Los Borja: família y mito, Alzira, Editorial Bromera.

Pagnotta, Laura (1977) Bartolomeo Veneto, L'opera completa, Florència, Centro di.

- (2002) The portraits of Bartolomeo Veneto, Seattle, University Washington Press.

Panoksky, Erwin (1969) Problems in Titian mostly iconographic, Phaidon Press, Londres.

Pope-Hennessy, John W. (1963) The portrait in the Renaissance, Londres, Phaidon.

Pozzi, Giovanni (1981) «Il ritratto della donna nella poesia d'inizio Cinquecento e la pittura di Giorgione» dins Pallucchini R. (ed.) Giorgione e l'umanesimo veneziano, Vol. 2, Florència, Leo S. Olschki, pp. 309-341.

Shteir, Ann B. (2006) «Iconographies of Flora: The Goddess of Flowers in the Cultural History of Botany» dins Shteir, A.B. / Lightman B. (eds.) Figuring it out. Science, Gender, and Visual Culture. Hanover, Dartmouth College Press, pp. 3-27.

Sinisgalli, Rocco (2011) Leon Battista Alberti: On Painting, a new translation and critical edition, Cambridge, Cambridge University Press.

Swarzenski, Georg (1922) Bartolomeo Veneto und Lucrezia Borgia, Frankfurt, Städel-Jahrbuch.

Urquízar, Antonio (2009) «El retrato en el Renacimiento», Goya, Fundación Lázaro Galdiano, n³28, pp. 271-274.

SCRIPTA, Revista internacional de literatura i cultura medieval i moderna, núm. 9 / juny 2017 / pp. 286-311

ISSN: 2340 - 4841 doi:10.7203/SCRIPTA.9.10348 
Alexandre Vico. Lucrècia Borja. L'alteració d'una identitat i l'errònia atribució de la pintura de Flora de Bartolomeo Veneto

Van der Sman, Gert Jan (2010) Lorenzo and Giovanna, Timeless Art and Fleeting Lives in Renaissance Florence, Florència, Mandragora.

Vasari, Giorgio (1881) Le Vite de più eccellenti pittori, scultori ed architettori, edició de Gaetano Milanesi, Vol. VII. Florència, Sansoni Editore.

Venturi, Adolfo (1894) «Pittori della corte ducale a Ferrara nella prima decade del secolo XVI», Archivio Storico dell'arte, VII, pp. 296-306.

- _. (1899) «Bartolomeo Veneto», Archivio Storico dell'arte, II, pp. 432-462.

Vigi, Berenice Giovanni (1981) «Lucrezia Borgia: ricerca di un’identità» dins Cultura figurativa ferrarese tra XV e XVI secolo a càrrec de Deputazione provinciale ferrarese di Storia Patria, Florència, Corbo e Fiore Editori, pp. 190-223.

Wyzewa, Teodor de (1891) «Le Mouvement des Arts en Allemagne et en Italie» Gazette des BeauxArts, Vol. V, serie 3, pp. 341-352. 